of the Atomic Nucleus by Spectroscopic Methods". After a short historical introduction, Dr. Tolansky discussed the spin of an atomic nucleus as one of the causes of the hyperfine structure of spectral lines. The importance of experimental technique in the study of hyperfine structure was stressed, attention being devoted to both sources and instruments. Typical hyperfine structures were illustrated and their interpretations discussed. It was pointed out that hyperfine structure investigations have yielded valuable information about nuclear moments, isotope abundance ratios, nuclear volumes and shapes of atomic nuclei. A theory of Landé was discussed according to which the spin and magnetic moments of atomic nuclei are determined by the spin and orbital motion of one neutron or proton only.

\section{Indian Association for the Cultivation of Science}

THE annual report of the Indian Association for the Cultivation of Science for the year 1941 includes the report of the committee of management and a list of papers published in the Indian Journal of Science, vols. 14 and 15, together with a report by Prof. K. S. Krishnan on the scientific work of the Association. This includes an account of magnetic studies on gadolinium sulphate octahydrate and of the spin-orbit coupling in cobaltous ions deduced from the magnetic properties of blue cobalt salts, in which results were obtained strongly supporting the theoretical prediction that there should be an inversion of the Stark pattern, first in a given cubic field as we pass from cobaltous to nickelous ions, and second for either of these ions as the disposition on the negative ions surrounding them changes from a tetrahedral distribution to an octahedral one. Reference is also made to magnetic measurements on a large number of cupric Tutton salts at low temperatures, in which also the cuprous ions possess practically the same type of anisotropy as in copper sulphate pentahydrate. The paramagnetic properties of several other salts of the iron group have been studied at low temperatures, and reference is made to the results obtained with some of the complex salts such as potassium ferricyanide. Preliminary measurements on the magnetic properties of mobile electrons in condensed ring hydrocarbons such as anthracene, chrysene, pyrene, etc., indicate that there is a decrease of the order of a few per cent of the diamagnetism of the mobile electrons as we pass from room temperature to about $300^{\circ}$. The metallie nature of the mobile electrons in aromatic molecules is supported by the observation that the absorption bands in the violet and in the near ultraviolet regions in anthracene crystals, presumably due to the mobile electrons, are paralleled by the strikingly selective refraction of the crystals in the region of these absorption bands, those wave-lengths that are strongly absorbed by the crystal being those that are strongly reflected from its surface. Measurements on the polarization of fluorescence of anthracene, phenanthrene, chrysene, and naphthacene in highly viscous solutions lead to the conclusion that the fluorescence is due either to a single linear oscillator or to a set of linear oscillators that radiate independently.

\section{Institute of Tropical Medicine at Havana}

THE August issue of the Boletin de la Medicina Sanitaria Panamericana contains an account of the Institute of Tropical Medicine of the University of
Havana. It was created on December 8, 1937, under the direction of Dr. Pedro Kouri, who is professor of parasitology and tropical diseases at the University. Its function is threefold: teaching, research and treatment. The courses of instruction are attended by students and post-graduates, many of whom are foreigners. Most of the research is devoted to studies of hookworm, echinococcus, bothriocephalus, ascaris, strongyloides, fasciola, amoeba and a new intestinal parasite first described in 1935, Inermucapsifer cubensis Kouri. The institute contains a Finlay Museum, which has a collection of anatomical specimens, parasites and other teaching material on permanent exhibition, laboratories, a department for drawing, photography, microphotography and microcinematography, and a free dispensary. In co-operation with other agencies, the institute carries on a campaign of popular education and prophylaxis against intestinal parasites. The official organ of the Institute is the Revista de Medicina Tropical.

\section{Recent Earthquakes}

A surgrt earthquake causing neither damage nor casualties took place at Almora in the United Provinces, India, on October 10, 1942.

A strong earthquake swarm has recently occurred in the Azores. All the islands have been affected, though the tremors were particularly violent in the Island of Fayal and in Sao Jorge. The shocks were continuing on October 17. Strong faulting has become apparent across the island of Fayal, and buildings have been affected. Further news is awaited from the islands and from seismological observatories.

\section{Announcements}

Prof. J. D. Bernal, professor of physics at Birkbeck College, University of London, will deliver the first Sir William Bragg Memorial Lecture of the Chemical Society on November 19 , at 2.30. The Lecture will be given at the Royal Institution, Albemarle Street, London, W.1.

Prof. P. A. Buxton, director of the Department of Entomology of the London School of Hygiene and Tropical Medicine, will deliver the first Bacot Memorial Lecture of the Lister Institute of Preventive Medicine on October 30 at 3 p.m. The Lecture, which will be entitled "Bacot's Work on the Louse and some of its Recent Developments", will be given at the London School of Hygiene and Tropical Medicine, Keppel Street, London, W.C.1, and is open to the public.

THE following appointments and promotions in the Colonial Service have recently been made: E. Bellis, agricultural officer, Kenya; S. H. Crowdy, agricultural superintendent, Gold Coast; A. C. Trueblood, agricultural officer, Nigeria; P. E. Weatherby, botanist, Uganda; B. C. Willis, agricultural officer, Northern Rhodesia; H. C. Dawkins, assistant conservator of forests, Uganda; B. Gilchrist, assistant conservator of forests, Tanganyika Territory; R. W. J. Keay, assistant conservator of forests, Nigeria ; G. A. Steven, fisheries development officer, Sierra Leone; C. L. C. Bourne (assistant chemist), government analyst, British Guiana; G. R. G. Kerr (senior assistant conservator of forests), conservator of forests, Nigeria; D. E. Faulkner (veterinary officer, Gold Coast), principal veterinary and agricultural officer, Swaziland; A. H. S. Vigo (senior assistant agricultural officer), agricultural officer, Nigeria. 